\title{
Actitudes homofóbicas entre los indígenas del Nuevo Mundo: los casos azteca, inca y mapuche en fuentes de los siglos XVI y XVII
}

\author{
Mauricio González Arenas y César Gamboa \\ Centro de Estudios Históricos, Universidad Bernardo O'Higgins \\ mauriciogonzalezarenas@gmail.com cesarandresgamboa@outlook.com
}

Recibido: 28 de agosto de 2014

Aceptado: 12 de enero de 2016

\begin{abstract}
RESUMEN
Este trabajo tiene como propósito aclarar una serie de imprecisiones historiográficas que, voluntaria o involuntariamente, han contribuido a confundir o a tergiversar el estudio de las actitudes de los indígenas americanos hacia las conductas homosexuales. Aquí se plantea, mediante el análisis de los casos azteca, inca y mapuche a través de fuentes de los siglos XVI y XVII, que América no fue en absoluto el paraíso homosexual que muchos han querido ver y dar a conocer. De esta manera, se proporcionan evidencias respecto de que la homofobia no fue inaugurada con la llegada de los españoles, sino que, por el contrario, ya estaba enraizada entre los indígenas desde antes de la aparición de los conquistadores europeos.
\end{abstract}

Palabras clave: Homosexualidad, sodomía, homofobia, indígenas, cronistas.

\section{Homophobic Attitudes Among Indigenous People in the New World: Aztecs, Incas and Mapuches Through $16^{\text {th }}$ and $17^{\text {th }}$ Century Sources}

\begin{abstract}
The purpose of this paper is to clarify a series of historiographical inaccuracies which, voluntarily or involuntarily, have contributed to confuse or distort the study of Native American attitudes toward homosexual behavior. It argues, analyzing Aztec, Inca and Mapuche attitudes from sixteenth-century and seventeenthcentury sources, that America was not at all the gay paradise that many have wanted to see and publicize. Thus, evidence is provided to support that homophobia was not inaugurated with the arrival of the Spaniards and that, on the contrary, it was already rooted among indigenous peoples since before the coming of the European conquerors.
\end{abstract}

Key words: Homosexuality, sodomy, homophobia, indigenous people, chroniclers.

Sumario: 1. Introducción. 2. La inmensa diversidad de las Indias. 3. Homofobia en el virreinato de Nueva España. 4. Condena y castigo de la homosexualidad en el virreinato del Perú. 5. Castigo de la homosexualidad entre los mapuches. 6. Conclusiones. 7. Referencia documental. 8. Referencias bibliográficas.

El salvaje está muy lejos de ser la criatura libre y despreocupada que nos pinta la imaginación de Rousseau. Por el contrario, se halla cercado por las costumbres de su pueblo, encadenado por tradiciones inmemoriales, no sólo en sus relaciones sociales, sino también en su religión, su medicina, su industria, su arte: en pocas palabras, en cada aspecto de su vida.

Edwin Sidney Hartland (1924: 138)

\section{Introducción}

El estudio del pasado de los pueblos indígenas de América debe lidiar con varios obstáculos que dificultan y entorpecen su entendimiento. En primer lugar, el historiador 
se encuentra con la versión distorsionada de su historia y cultura contenida en documentos producidos por europeos que no siempre comprendieron lo que describían. Claude Lévi-Strauss estuvo acertado al reconocer que el historiador y el arqueólogo nunca entrarán «en contacto con una civilización desaparecida, sino solamente a través de los documentos escritos o de los monumentos figurados que esta sociedad $-\mathrm{u}$ otras- habrán dejado sobre sí» (1951: 13-14). La falta de contacto directo tiene como consecuencia que el conocimiento certero de las costumbres de los pueblos sin escritura sea de muy difícil consecución. Esto constituye una primera precaución que todo historiador debe mantener presente en sus investigaciones.

En segundo lugar, la acumulación bibliográfica surge como otro obstáculo, puesto que va asentando interpretaciones que muchas veces adquieren valor de versión definitiva, aceptadas por nuevos investigadores que las toman como punto de partida para sus propios trabajos. La aceptación de preceptos de este tipo ha conducido en demasiadas ocasiones a sostener como verdades inamovibles ideas que una revisión más precisa de las fuentes permite rebatir fácilmente. Este problema se produce en todas las disciplinas y áreas del conocimiento donde existen tópicos ya aceptados que encuadran la investigación y la guían por caminos preconcebidos, dando forma a los «obstáculos epistemológicos», al decir de Bachelard (1997).

En el caso específico de las actitudes de los naturales del Nuevo Mundo hacia la homosexualidad, en el momento de la llegada de los españoles a fines del siglo XV, se han instalado algunas interpretaciones casi sin cuestionamiento y contradictorias entre sí. Por lo menos tres perspectivas deben ser tenidas en cuenta, puesto que agrupan las principales corrientes historiográficas que han abordado el tema y constituyen el punto de partida de toda nueva investigación.

Una primera interpretación ha sostenido que los españoles atribuyeron a los pueblos americanos una sexualidad contraria a los preceptos cristianos con el fin de justificar y legitimar su sometimiento (Garza Carvajal 2003: 132). Fernanda Molina sintetizó esta perspectiva, señalando que los españoles asociaron «a las sociedades locales con la práctica de la sodomía, pero también con un conjunto de pecados de la carne que incluía el incesto, las orgías, la poliginia, los sacrificios humanos y las borracheras, que fungieron de 'causas justas' para su sometimiento militar, político y religioso» (2011: 186). En un trabajo anterior, Molina ya había adelantado que los tratadistas se valieron de estas acusaciones «para demostrar la necesidad de hacer la guerra contra los indios, nutriéndose de los testimonios, directos o indirectos, que los cronistas aportaron a través de sus obras» (2010: 5-6). Así, esta autora transforma las afirmaciones de conquistadores y cronistas en acusaciones interesadas y no diferencia en ellas las observaciones de la realidad indígena de los juicios de valor que ella despierta en los escritores indianos.

Pete Sigal, por el contrario, ha utilizado las crónicas españolas para defender la idea de que, al menos entre los naturales de Nueva España, el sexo entre hombres era totalmente aceptado e incluso exaltado mediante su inclusión en la mitología. Sigal ha interpretado las mismas afirmaciones hispanas en sentido inverso al de Molina, señalando que ellas no son falsas acusaciones, sino el testimonio furtivo de que entre los nativos no existían prescripciones en contra de las prácticas sexuales entre hombres. De acuerdo con sus propias palabras, «las múltiples construcciones de la 
homosexualidad en estos textos emergieron de un discurso colonial que obscurece las visiones autóctonas de las sociedades indígenas de México» (Sigal 2005: 560). Curiosamente, a pesar de su tesis principal, Sigal también incluye una mención de que los conquistadores habrían utilizado la acusación de sodomía en contra de los indígenas para legitimar y justificar su conquista (2005: 560-561).

Finalmente, una tercera posición se ha centrado en aquellos documentos españoles que sostienen que entre los naturales se practicaba la homosexualidad, pero que, al mismo tiempo, ésta era prohibida y castigada. Con el fin de explicar esta aparente contradicción, concluyen que el discurso cristiano occidental se inmiscuyó en la cultura nativa para transformar a los indios, como seres influenciables, en los que la aculturación generó el surgimiento de dichas regulaciones del comportamiento sexual. «Los nativos en definitiva enunciaron creencias europeas en una mimetología que los minaba aun cuando las producían» (Goldberg 1991: 51). Es decir, cuando castigaron las relaciones entre hombres fue porque la normativa cristiana se filtró en su cultura, no por propia definición.

Al examinar estas tres perspectivas, resulta evidente que cada investigador ha utilizado los argumentos que le son favorables a sus propios planteamientos, aún a costa de forzar las fuentes documentales, olvidando «el embrollo de contradicciones en que se enredan los escritores de la conquista al hablar de los naturales de estas tierras» (Oliva de Coll 1976: 17).

Al contrario de los estudios reseñados, este trabajo se centra en las muchas voces que testificaron y revelaron que los indígenas aborrecían las prácticas homosexuales per se y no por influencia de los hispanos. A partir de ellas, se refutan los dos principales tópicos de la historiografía occidental a este respecto: 1) la idea de que la homosexualidad era una práctica extendida, tolerada e incentivada entre los indígenas de América y 2) que las persecuciones, los castigos y la homofobia en general se iniciaron con el arribo de los conquistadores europeos.

Este trabajo surge de la constatación de que los españoles reconocieron la diversidad de culturas de los indígenas del Nuevo Mundo y, en consecuencia, no atribuyeron una naturaleza idéntica a todos los pueblos. A partir de lo anterior, se propone que los autores indianos coincidieron en sus observaciones y plasmaron que los nativos, salvo muy pocas excepciones, tenían rígidos sistemas morales que prohibían y castigaban la homosexualidad. Para abordar esto, se recurre al examen de las actitudes frente a la homosexualidad en Nueva España, Perú y entre los mapuches del Sur de Chile, como ejemplos que permiten ilustrar la hipótesis de este trabajo.

\section{La inmensa diversidad de las Indias}

El estudio de la concepción que los españoles tuvieron de los indígenas del Nuevo Mundo adolece de una seria malformación metodológica que se construye por medio de la selección de extractos de los cronistas y escritores indianos con la finalidad de producir una versión única, como si cada uno de los autores revisados tuviera una perspectiva idéntica a la de todos los demás. 
En contraste con la homogeneidad ilustrada por los historiadores, Gonzalo Fernández de Oviedo, uno de los más duros acusadores de los indios, reconoció un hecho indubitable: «que hay en este imperio de las Indias... tan grandes reinos y provincias y de tan extrañas gentes y diversidades y costumbres y ceremonias e idolatrías, apartadas de cuanto estaba escrito (desde ab initio hasta nuestro tiempo): que es muy corta la vida del hombre para lo poder ver» $(1851-55,1: 2)$. La diversidad parece ser motivo de admiración y sorpresa para el escritor indiano.

Bernabé Cobo también reparó en esa diversidad cultural de los pueblos del Nuevo Mundo y describió ese continente como «tierra tan grande y extendida, con tanta variedad de climas y temperamentos, habitada de infinitas gentes, diferentes en lenguas, costumbres y ritos» (1964, Lib. 2: 11). A pesar de que Cobo contrastó esta diversidad cultural con lo que pareció era una coincidencia en el aspecto, color y figura, el punto importante de su referencia es la afirmación de la diferente organización cultural de cada uno de estos pueblos.

Sin embargo, esta diversidad identificada por Oviedo y Cobo pasó desapercibida para todos aquellos que, como Francisco López de Gómara, trataron de hacer de ella una sola realidad uniforme. Según Joseph de Acosta, «tratar los hechos e historia propia de los Indios, requería mucho trato y muy intrínseco con los mismos Indios, del cual carecieron los más que han escrito de Indias» (1894, I: xiii). Esta falta de contacto directo con la realidad indígena del Nuevo Mundo constituye un aspecto que pocos historiadores han considerado al utilizar las crónicas en el estudio de la sexualidad de estos pueblos.

El comentario de Acosta es especialmente pertinente si se considera la concepción que existía sobre las fuentes de la historia en su tiempo, puesto que «ser testigo de vista tenía una larga tradición en Occidente: propuesta por los clásicos, se había convertido en una de las 'fuentes' primordiales de la historia medieval, la cual era valorada por encima de cualquier otro tipo de información» (Borja Gómez 2002: 71). En aquellos tiempos, ya había consciencia de que los escritores indianos que no tenían experiencia directa en el Nuevo Mundo no conocían sus minucias del mismo modo que aquellos que habían pasado una larga vida en los territorios ultramarinos. Esto queda bien ejemplificado en lo sucedido con Francisco López de Gómara quien, en 1552, puso en circulación una caricatura de los indígenas donde enfatizó características consideradas negativas, entre las cuales la sodomía aparece en lugar protagónico (1979: 7). Esta misma imagen fue luego revitalizada con lo planteado por el Conquistador anónimo en 1556. Ambos «testimonios sobre la existencia de la homosexualidad en el corazón del imperio azteca son dudosos, proviniendo de un primer autor que tiene por costumbre las caricaturas negativas a propósito de los indios y de un segundo autor cuya imaginación es fértil y su tendencia a la exageración evidente» (Mari 1986: 10). No se olvide que López de Gómara jamás visitó el Nuevo Mundo y sobre el Conquistador anónimo no se tienen mayores referencias.

Todo lo anterior viene a probar que los españoles no concordaban en su mirada sobre los indígenas del Nuevo Mundo y tenían puntos de vista divergentes -especialmente en lo referido a la valoración- sobre las sociedades allí encontradas. Por lo tanto, cada escritor indiano dejó registro de su propia perspectiva, no siempre concordante con la del resto. «Conquistadores de la primera hora, gobernantes, juristas, 
eclesiásticos y conquistados nos han transmitido lo que cada cual hizo, vio y pensó» (Tomás y Valiente 1994: 240). Por lo tanto, ni existe una única visión española de los naturales ni tampoco los españoles más avezados eran tan ingenuos como para pensar que en todas las comarcas indianas vivían los mismos hombres.

Si los historiadores han sostenido que los conquistadores y escritores indianos propiciaron una imagen negativa, en la cual «consideraron que todos los indios eran hiper sexuados y acusaron a los hombres indios de practicar la sodomía, la pederastia y la poligamia» (Howey 2007: 222), la lectura y consulta directa de estos registros hacen pertinente preguntar si estas fuentes confirman o no tal pronunciamiento. Al hacerlo, se debe distinguir entre quienes escribieron sin conocer el Nuevo Mundo y quienes lo hicieron a partir de sus propias experiencias, para reconocer «por lo menos, el efecto que tuvo en algunos la experiencia de campo» y «evocar la lucidez de una visión personal frente al estereotipo» (Bernand y Gruzinski 1992: 23).

\section{Homofobia en el virreinato de Nueva España}

Pete Sigal ha argumentado que los nahuas construyeron una cosmología que respaldaba el actuar homosexual y que esto se comprueba en la atribución de prácticas homosexuales a los dioses, según se constata en el Códice Florentino que contiene la versión en náhuatl de la obra de Bernardino de Sahagún (Sigal 2005, 2007). Según este autor, la narración contenida en el texto compilado por Sahagún sobre Tezcatlipoca/Titlacauan, en la cual éste último es designado como cuiloni (homosexual), prueba su tesis (2007: 26-27). Para refutar y descartar las afirmaciones de aquellos escritores que señalaron que los nahuas repudiaban la homosexualidad, Sigal escribió que «todas estas aseveraciones fueron hechas por nahuas y mestizos educados por europeos a lo menos una generación después de la conquista» (2005: 593).

Dos argumentos se deben esgrimir para demostrar que la visión de Sigal no se corresponde con la práctica nahua, que, al contrario de lo que este autor sostiene, se basaba en un claro repudio de la homosexualidad. El primer argumento es de tipo comparativo: en otras culturas, la penetración de un dios se incluye en la mitología como vejación y forma de sometimiento y no como consagración del sexo anal. El segundo argumento es que todos los cronistas, incluso el propio Sahagún, señalan que los nahuas aborrecían a los hombres que saciaban su apetito sexual con otros hombres.

Con respecto al primer argumento de tipo comparativo, el uso mitológico de la penetración anal como una ofensa que implica el sometimiento del penetrado tiene varios antecedentes en el registro histórico. El más conocido es el mito egipcio de Horus, surgido hace más de cuatro mil años durante el reinado de las dinastías $\mathrm{V}$ y VI (Baines y Málek 1998: 36-37). Según los fragmentos 155 y 183 de un texto de la pirámide del faraón Unis, entre los dioses Horus y Seth existía una oposición que se zanjó en una lucha en la cual Horus, tras perder un ojo, terminó derrotando y cercenándole los testículos a Seth (Allen 2005: 39-52). Y en el fragmento 396, ahora de un texto de la pirámide de Pepi I, se lee que «Horus transportó su semen dentro del ano de Seth»y «Seth transportó su semen dentro del ano de Horus» (Allen 2005: 146). 
Por supuesto, el mito en sí nada dice sobre la visión que los egipcios tenían sobre la homosexualidad, pero su contexto permite sostener el punto defendido: la penetración anal aparece como un acto de agresión y de dominación, en el cual, el individuo que penetra es quien logra la supremacía. El coito y el semen mismo se deben entender como acción e instrumento de poder y realización. Entre los egipcios, la «agresión fálica no era meramente considerada como una humillación: la implantación de semen en el cuerpo de otro hombre era equivalente a ganar poder sobre él» (Manniche 1977: 14).

Para el caso de la Nueva España, Gregorio García se encargó de señalar que en las «dos o tres provincias» en donde se practicaba la sodomía, ésta se realizaba principalmente porque el demonio les habría hecho creer a los indígenas que «los dioses que adoraban hicieron eso mismo, y que así era lícito y bueno» (1607: 281). Esta afirmación de García, en principio, sustenta la afirmación de Pete Sigal sobre el entendimiento que los indígenas habrían tenido de sus dioses; no obstante, relativiza todo el argumento al definir que esta idea se propagó solamente en dos o tres provincias. Más aun, el mismo autor sostiene, acto seguido, que «con todo eso siempre se tuvo por abominable y feo este pecado» (García 1607: 281). El propio Sigal reconoce que Tezcatlipoca, bajo la forma de Titlacauan, «es burlado e insultado en sus intentos de ser un gran guerrero, capturar y sacrificar a otros» y es ritualmente «sodomizado y feminizado en cuanto es capturado, sacrificado y comido» (2005: 572). No se olvide que el propio Sahagún registra que «algunos, cuando perdían su hacienda, con desesperación reñían a Tezcatlipoca y decíanle: 'Tú, Tezcatlipoca, eres un puto; ya hazme burlado y engañado'» (Sahagún 1829, tomo I, Lib. IV, Cap. IX: 300). El hecho concreto es que el epíteto se dirige al dios como insulto y no como reconocimiento de un actuar que debiera ser imitado. Esto coincide con lo estudiado por Pierre Bourdieu, quien ha analizado en profundidad la concepción de la penetración anal como un insulto o forma de humillación aplicada sobre otros hombres y ha sostenido «que, en muchas sociedades, la posesión homosexual se concibe como una manifestación de «poder», un acto de dominación» (Bourdieu 2000: 25).

En cuanto al segundo argumento, los cronistas casi en bloque sostienen que los naturales de Nueva España aborrecían con firmeza a homosexuales y lesbianas y, más aun, que en la mayor parte de los territorios se les castigaba duramente. Por ejemplo, con respecto al desprecio hacia las prácticas homosexuales, Bartolomé de Las Casas, al hablar de los sacerdotes aztecas, no sólo destaca su honestidad, su virtuosismo y su sobriedad, sino también el hecho de no mantener ningún tipo de relación carnal ni con mujeres ni mucho menos con hombres, ya que para ellos esta práctica era algo «odiosísimo y abominable» (1909, Cap. CXXXVIII: 366). Algo similar sostiene Juan de Torquemada, quien señaló que si algún sumo sacerdote o pontífice era sorprendido en prácticas deshonestas con una mujer era inmediatamente privado de sus bienes y desterrado, y si era sorprendido en prácticas sodomíticas era, dependiendo de la región, quemado o ahorcado (1723, Lib. 12, Cap. 4: 380).

Otro ejemplo del aborrecimiento de los indígenas hacia la homosexualidad lo encontramos en la ciudad de Tlaxcala. Sobre esta localidad, Diego Muñoz Camargo señaló que al deleite sexual entre varones los tlaxcaltecas lo consideraban «grande abominación», agregando que, si bien los sodomitas no eran físicamente castigados, 
sí eran, en cambio, mal mirados y tratados como mujeres. Más aun, Muñoz Camargo escribió que a los hombres sorprendidos en «pecados contra natura» se les tildaba de «malditos y desventurados», y que a modo de ofensa se les preguntaba si acaso en el mundo había «falta de mujeres» para que ellos tomaran «el oficio de mujer» (1892, Lib. I, Cap. XVI: 138).

En relación con esta aparente condescendencia con la sodomía, fray Bartolomé de Las Casas igualmente apuntó que en algunas provincias del imperio azteca esta práctica era medianamente tolerada o disimulada, pero inmediatamente señala que la acción en sí fue siempre mal mirada y sus practicantes tachados de «hombres muy viles y muy infames» (1909, Cap. CCXIII: 557). La misma apreciación sostiene Gregorio García, quien señala que si bien en algunos lugares la práctica no era castigada, quien la cometía era invariablemente «tenido por infame» (1607: 281-282). Y por su parte, Juan de Torquemada también señala que «los hombres afeminados y mujeriles en hábito» era menospreciados y debían convivir únicamente con mujeres y realizar «oficios de mujeres» (1723, Lib. 10, Cap. 35: 299).

Pero esta relativa «tolerancia», al parecer, sólo se daba en Tlaxcala y en algunos pocos lugares más, ya que, según los testimonios, a lo largo de todo el virreinato de Nueva España los indígenas poseían una serie de normas que condenaban y castigaban severamente el contacto sexual entre hombres. Así por ejemplo, Bartolomé de Las Casas señala que en gran parte de los antiguos dominios aztecas aquellos que eran sorprendidos cometiendo el nefando crimen, tanto el penetrador como el penetrado, terminaban pagando la acción con su vida (1909, Cap. CCXIII: 557).

Para el caso particular del sujeto paciente (penetrado) del acto homosexual, Bernardino de Sahagún señala que éste era un ser abominable, detestable y digno del escarnio y el maltrato de la gente; agregando, por si fuera poco, que «el hedor y la fealdad de su pecado nefando no se puede sufrir por el asco que da a los hombres» (Sahagún 1830, tomo III, Lib. X, Cap. XI: 26). Algo similar sostiene Andrés Pérez de Ribas, quien señala que en general el pecado nefando era considerado por los indígenas como un «vicio inmundo», pero que entre ellos eran principalmente los «pacientes» quienes eran conocidos, menospreciados e insultados «con vocablo y palabra afrentosa» (1645: 11). En una relación de las leyes de los naturales de Nueva España, escrita en 1543 por fray Andrés de Alcobiz, se indica que «al puto o somético y al varón que tomaban en hábito de mujer» lo ahorcaban (Alcobiz 1891: 311).

Si bien los dos pasajes citados no hacen una alusión clara y directa en torno al «agente» penetrador del acto sodomita, Bartolomé de Las Casas se encarga nuevamente de remarcarnos que en el virreinato de Nueva España ahorcaban tanto al que «tomaba el hábito de mujer» como al que «cometía el pecado nefando» en general, es decir, tanto al agente activo (penetrador) como al agente pasivo o paciente (penetrado) (1909, Cap. CCXV: 563).

Junto con sentenciar que en todos los dominios aztecas, en especial en México y Texcoco, la sodomía fue constantemente perseguida y castigada, Las Casas señala que el padre del en esa época señor de Texcoco ajustició a los sodomitas que halló en sus tierras (1909 Cap. CCXIII: 557). Esta aversión que al parecer existía en Texcoco hacia la sodomía, es corroborada por Fernando de Alva Ixtlilxochitl, quien registró que en este pueblo el pecado nefando «se castigaba con grandísimo rigor, pues el 
agente era atado en un palo [y] lo cubrían todos los muchachos de la ciudad con ceniza, de suerte que quedaba en ella sepultado, y al paciente por el sexo le sacaban las entrañas, y asimismo lo sepultaban en la ceniza» (1891-92 II: 187-88). Esta misma información fue reproducida años después por fray Juan de Torquemada (1723, Lib. 2, Cap. LII: 166).

Que la pena de muerte era el ineludible castigo para el acto sodomítico, es algo sostenido por el ya mencionado Juan de Torquemada, quien destacó que al sujeto sorprendido practicando el pecado nefando lo ahorcaban, ya que dicho acto era tenido por bestial y ajeno a toda razón (1723, Lib. 12, Cap. IV: 380). Por lo demás, este mismo autor señaló que «el hombre que vestía hábitos de mujer moría ahorcado; y lo mismo la mujer que se ponía en hábitos de hombre» (1723, Lib. 12, Cap. IV: 380).

En el caso puntual de las relaciones sexuales entre mujeres, al parecer los castigos no distaban mucho de los aplicados a los hombres. Según Gregorio García, «si una mujer pecaba con otra» a ambas les daban de palos o bien las ahogaban (1607: 281). Por su parte, Torquemada igualmente sostiene que a las mujeres que practicaban el lesbianismo se les llamaba patlache y que ambas morían en caso de ser sorprendidas en la práctica (1723, Lib. 12, Cap. IV: 380-381).

Por lo demás, estas implacables leyes que prevalecían entre los indígenas de Nueva España, se caracterizaban por ser aplicadas a todo aquel que fuera sorprendido en la infracción, sin distinción de clase. Por ejemplo, Alonso de Zorita señaló que, por razones formativas, los hijos de los reyes eran castigados con mayor rigor que la gente común a la hora de ser sorprendidos en prácticas homosexuales reseñando, a modo de ejemplo, el caso de un hijo de Nezahualcoyotzin quien, a pesar de su valentía y bravura, al ser acusado de perpetrar el pecado nefando fue juzgado y ejecutado por orden del Consejo, sentencia que fue ratificada por su propio padre (Zorita 1891: 31).

Más adelante, Zorita afirma que aquellos «que cometían el pecado nefando eran sin remisión muertos; y era tan abominado entre ellos este delito que la mayor afrenta y baldón que uno podía hacer a otro era llamarlo cuilón, que quiere decir puto en nuestra lengua» (1991: 32). Este mismo autor, en otro de sus escritos, señala que uno de los señores de Texcoco, «por razón natural aborrecía el pecado nefando y mandaba matar a los que lo cometían» (Zorita 1909: 63).

En general, la gran mayoría de las fuentes consultadas confirman que los naturales de la Nueva España condenaban y castigaban implacablemente el afeminamiento y las relaciones sexuales entre hombres. Ahora bien, si en lugares como Tlaxcala estas prácticas no eran del todo sancionadas, ello no significa que fueran abiertamente toleradas, ya que los infractores no se libraban de ser sometidos a una férrea condena social.

\section{Condena y castigo de la homosexualidad en el virreinato del Perú}

Bajando hacia las zonas meridionales del Nuevo Mundo, en los antiguos dominios del Imperio del Tahuantinsuyo, el panorama observado y registrado por los hispanos, en cuanto a las costumbres nativas, no parece variar en demasía en comparación a lo observado en el septentrión. Por todas partes se observa no solo una gran pluralidad 
de paisajes sino también una gran diversidad de grupos humanos, poseedores de tradiciones y costumbres igualmente diversas.

Según la documentación, en los antiguos dominios del Inca la «sodomía» era una práctica conocida, pero no generalizada o universalmente aceptada. Muy por el contrario, uno de los puntos de comunión registrado por los cronistas reposa en el hecho de que en casi todas las regiones exploradas la homosexualidad era más bien disimulada por sus usuarios o, como señaló el Inca Garcilaso de la Vega, practicada «en mucho secreto» (1976, Lib. VI, Cap. XI: 30-31), ya que generalmente era recelosamente tolerada por la población o, en la mayoría de los casos, abiertamente resistida, juzgada y castigada.

La no universalidad de la aceptación de la sodomía en las tierras incaicas se advierte en varios testimonios. Según Agustín de Zárate, había «memoria entre los indios, descendiendo de padres en hijos», sobre unos gigantes que habitaban el sector de Puerto Viejo y de Punta Santa Helena, quienes por ser «muy dados al vicio contra natura» habrían sido eliminados por orden divina de la faz de la tierra (Zárate 1862 Lib. I, Cap. V: 465). Más tarde, Pedro Cieza de León (2005: 182) completó un cuadro en el que prevalece ampliamente la diversidad de costumbres y la particularidad de cada grupo humano, ratificando la existencia de sodomitas en la zona señalada por Zárate, pero haciendo hincapié en que la práctica no se realizaba en todos los pueblos, sino sólo en algunos, visión también compartida por fray Bartolomé de Las Casas, quien puntualizó que en Puerto Viejo sólo algunos nativos «y no todos cometían el tal vicio» (1909, Cap. CCXLVIII: 649). Esta misma perspectiva fue refrendada años más tarde por el Inca Garcilaso, quien señaló que el acto sodomítico era «usado entre pocos» (1976, Lib. VI, Cap. XI: 31). Y siempre en esta línea, Cieza de León (2005: 356) hace gala de una gran dosis de sentido común cuando sentencia que homosexuales se encontraban por todo el mundo, no solamente en el Perú.

Los españoles no fueron ciegos a las diferencias que encontraban en cada nuevo territorio que exploraban, lo que se expresa en la relación que fray Domingo de Santo Tomás hiciese a Cieza de León sobre algunos templos y lugares sagrados repartidos principalmente en la sierra, donde existían hombres que desde temprana niñez eran obligados a usar vestimentas de mujer y eran penetrados en ocasiones sacras por «señores y principales» (Cieza 2005: 183).

En la relación citada por el cronista, el autor pareciera enfatizar que estos hombres únicamente accedían a ser penetrados por estar obligados y por habérseles hecho creer desde niños que aquello era una «especie de santidad y religión» (Cieza 2005: 183). Esta cita podría dar a entender que, entre los pueblos sometidos al Inca, esta práctica era habitual; sin embargo, Cieza de León sostiene que era sólo llevada a cabo en algunas provincias sometidas al Tahuantinsuyo.

Con todo, Cieza de León es claro en señalar que la sodomía, aunque practicada por algunos, era ampliamente rechazada y castigada por los nativos de las zonas que visitó, quienes lo tenían por un acto de «gran fealdad y no lo acostumbran, antes lo aborrecen» (2005: 285). El cronista además asevera que quienes lo practicaban eran mirados en menos, tachados de sucios, tildados de afeminados y tratados, a modo de afrenta, como mujeres (Cieza 2005: 83, 168, 178, 217). De hecho, fray Bartolomé de 
Las Casas sostuvo que los propios indígenas rechazaban la unión sexual entre hombres por considerarla «cosa vilísima» (1909, Cap. CCXLVIII: 649).

Cieza de León resalta que los Incas, junto con no practicar el pecado, «aborrecían a los que lo usaban, teniéndolos en poco como a viles apocados y que si por ellos era sabido de alguno que tal pecado hubiese cometido lo castigaban con tal pena que fuese señalado y conocido entre todos» (2005: 356). Esta fobia de los monarcas cuzqueños hacia aquellos que se entregaban al deleite carnal entre varones, es reafirmada igualmente por el Inca Garcilaso de la Vega, quien, al relatar las conquistas de los soberanos del Tahuantinsuyo, registró que en la provincia de Huailas el Inca Cápac Yupanqui castigó severamente a ciertos aborígenes que guardando el mayor disimulo «usaban el abominable vicio de la sodomía» (1976, Lib. VI, Cap. XI: 30-31).

Información similar entrega Antonio Vázquez de Espinosa, según el cual este mismo Cápac Yupanqui, tras enterarse que algunos de los habitantes de los valles que acababa de conquistar practicaban la homosexualidad, ordenó quemar vivos a los culpables $\mathrm{y}$, posteriormente, arrasar sus casas y esparcir sal en la tierra «para que sólo quedase memoria del castigo» (1948: 1545). Martín de Murúa, a su vez, indicó que Lloque Yupanqui sancionó «con grandísima severidad los pecados públicos -hurtar, matar-y sodomía, por los cuales acotaba, desorejaba, desnarigaba y ahorcaba, y a los nobles y principales cortaba el cuello o rasgaba la camiseta» (1962-64, Lib. I, Cap. VII: 52).

En el mismo sentido, un grupo de indígenas, todos interrogados por orden del Virrey Francisco de Toledo, declaró que cuando los Incas descubrían a alguien ejercitando la proscrita acción, lo castigaban duramente a orillas de un río, con el fin de que se ahogara («Información de las idolatrías...» 1874: 160). Otro grupo respondió que a los culpables de practicar sexo entre hombres «los Incas los hacían castigar ahorcándolos» (ibid.: 213). Y un tercer grupo sostuvo que a los sodomitas los «Incas los mandaban matar» (ibid.: 202, 203).

Diego de Rosales escribió que el motivo de una sequía de siete años acaecida durante el reinado de Pachacutec, fue el excesivo incremento del «vicio de la Sodomía», razón por la cual, estas «abominables torpezas» [...] «no merecían sino fuego» (1877: 336). Y esto fue precisamente lo que realizó el mentado Pachacutec al llegar a la localidad de Huailas, lugar en donde, según Vázquez de Espinosa, «quemó algunos sométicos que había para que con el castigo se enmendasen y hubiese escarmiento» (1948: 1556).

Al volver al interrogatorio ordenado por el Virrey Toledo, a fin de confeccionar un informe que registrara las costumbres e idolatrías de los indígenas, resulta interesante destacar que en éste había dos preguntas relacionadas directamente con la sodomía («Información de las idolatrías...» 1874: 135). Y más interesante resulta que los cinco grupos de indígenas interrogados, respondieron que en todas partes había rastros y registros de hombres que practicaban sexo con otros hombres, pero que entre la mayoría de ellos esto era un comportamiento mal visto.

Atendiendo a las declaraciones entregadas por los consultados, uno de los grupos declaró haber escuchado que en algunas zonas efectivamente había hombres que practicaban la homosexualidad, pero que ellos no los habían visto, que no sabían si se vestían de mujeres, si se depilaban o si los castigaban por su conducta («Información de las idolatrías...»1874: 188). Otro de los grupos interrogados sostuvo que los sos- 
pechosos de oficiar de agente pasivo en una relación homosexual no eran castigados físicamente, sino que eran catalogados peyorativamente de «oruas» y pasaban a ser un objeto permanente de risas y burlas (ibid.: 148). En cambio, otros tres grupos señalaron que aquellos sorprendidos ejerciendo la proscrita práctica eran cruelmente castigados o asesinados (ibid.: 160).

En general, la condena y castigo a la práctica homosexual se extendía a todos los territorios incaicos, constituyéndose en uno de los pecados más vituperables. De hecho, una relación anónima que data aproximadamente de entre 1615 y 1621, señala que entre los pecados que los súbditos del Inca debían confesar estaba «cometer el nefando con hombre o bestias» (Anónimo 1879: 167). La misma relación, al enumerar las leyes del antiguo Perú, enuncia el siguiente precepto: «Quien cometiere el pecado de sodomía, que muera arrastrado y ahorcado, y luego sea quemado con todos sus vestidos, y lo mismo si se juntare con alguna bestia» (Anónimo 1879: 203).

En los vastos territorios del virreinato limeño la homosexualidad era conocida y practicada por muchos. Sin embargo, si bien en algunos lugares el acto se realizaba sin una excesiva condena o persecución social, en general, en la gran mayoría de los territorios sometidos al Inca, la homosexualidad era tan o más condenada que entre los propios hispanos. De hecho, los castigos aplicados a quienes eran sorprendidos en los placeres carnales entre varones no iban a la zaga, en contundencia y crueldad, a los aplicados a lo largo y a lo ancho del mundo cristiano.

\section{Castigo de la homosexualidad entre los mapuches}

El historiador Diego Barros Arana estableció en Chile lo que vino a ser un tópico perdurable de la historiografía conservadora: la atribución a los mapuches de conductas desenfrenadas, según su propia visión, entre las cuales resaltó la homosexualidad. «Sin duda -generalizó Barros Arana-, los indios de Chile eran entonces tan bárbaros como las tribus más groseras que los conquistadores hallaron en América». Para el historiador decimonónico, los nativos chilenos tenían las mismas costumbres que atribuía de manera universal a quienes se consideraba entonces como salvajes y habló de «ciertas costumbres groseras y vergonzosas, que degradan al hombre y que parecen a primera vista ajenas de un pueblo vigoroso y guerrero». Por supuesto, Barros Arana se refiere a «los vicios degradantes llamados contra naturaleza», que se «encontraron en casi toda la América», pues «la insistencia con que hablan de ellos los que primero estudiaron las costumbres de los indios de Chile, no deja lugar a duda». Tal fue el juicio emitido por el padre de la historiografía chilena (Barros 1884-1902, I: 59, 105).

Los ecos de esta visión fundadora han sido perdurables en la posterior escritura historiográfica, siendo su más reciente representante el galardonado historiador Sergio Villalobos, quien ha repetido que tanto en las celebraciones por triunfos militares como en las de carácter religioso, los mapuches abusaban en exceso de la comida y la bebida, lo que a la postre daba paso a todo tipo de desenfreno sexual, incluyendo los incestos y la homosexualidad, práctica que, según el autor, estaba «muy difundida» (Villalobos 2006: 21). 
Al revisar las crónicas y la documentación hispana, es posible advertir que gran parte de las afirmaciones de Villalobos son una copia casi calcada de la crónica de Alonso González de Nájera (1889: 445-446), quien residió en Chile entre finales del siglo XVI y comienzos del XVII. Sin embargo, a pesar de la nula simpatía que el cronista que comentamos sentía por los indígenas, en su crónica no se refiere en absoluto a la práctica homosexual, lo que termina dejando sin una fuente clara la tajante afirmación de Villalobos sobre la supuesta homosexualidad general de los mapuches.

Según Barros Arana, Miguel de Olaverría fue el pionero en el estudio de las costumbres de los indígenas de Chile y, en nota a pie de página, lo refirió para sustentar la acusación de que éstos practicaban generalizadamente el sexo entre hombres. Sin embargo, luego de revisar este documento, se puede observar que Olaverría, al escribir sobre los mapuches, jamás afirmó lo referido por Barros Arana. Por el contrario, Olaverría sostuvo claramente en su informe que la «sodomía» era uno de los dos únicos delitos, junto con la hechicería, que los linajes mapuches sancionaban con la pena de muerte: «Han sido regidos y lo son particularmente los que ahora sustentan la guerra por sus leyes naturales usadas por sus mayores que ninguna se extiende a dar muerte si no en caso de sodomía o hechicería» (AGI, Patronato, 228, R. 13, f. 3r).

Por lo demás, y en contraste con lo afirmado por Barros Arana, Olaverría escribió que los mapuches eran «viciosísimos en mujeres y usan de muchas sirviéndose como de esclavas sin hacer más regalo a una que a otra» (AGI, Patronato, 228, R. 13, f. $3 r$ ). Más adelante, el oficial español agregó, entre las razones por las que los indios «continúan en su rebelión», que una de ellas era no «recibir nuestra santa fe católica por sola consideración de entender que les defenderá el tener muchas mujeres que es su cielo y elemento, dejándoseles solamente una, que por lo demás bien saben y conocen como yo lo he platicado con muchos de ellos que es buena, limpia y conforme a buena razón» (AGI, Patronato, 228, R. 13, f. 9r).

Lo anterior coincide con lo informado en 1614 por fray Juan Falcón, quien permaneció entre los mapuches en calidad de prisionero alrededor de quince años. Ante la pregunta de los miembros del Cabildo de Santiago en torno a las razones por las cuales los indígenas no aceptaban la paz ofrecida por los españoles, Falcón contestó que, además de la soberbia propia de los mapuches, «es porque les parece que dándola [la paz] han de vivir cristianamente con una sola mujer debajo de matrimonio y no han de hacer las maldades que hacen ahora y por esto lo rehúsan porque generalmente son demasiadamente dados a todo género de vicios especialmente el de la carne y así tienen muchas mujeres que es toda su felicidad para la satisfacción de sus sensualidades y para que les hagan mucha chicha para beber y no quieren ni desean otra cosa» (Zapater 1988: 323).

Un par de décadas después del informe de Olaverría y de la declaración de Falcón, el joven capitán español Francisco Núñez de Pineda y Bascuñán fue hecho prisionero por los mapuches -tras la desastrosa derrota infringida por éstos al ejército español en 1629, en la batalla de Las Cangrejeras-. Durante su estadía entre los naturales, el bisoño oficial observó y tomó nota no sólo de las vicisitudes de su cautividad sino también sobre las tradiciones, las costumbres y, en general, sobre la forma de vida de sus captores. Posteriormente, tras su liberación -ocurrida cerca de un año después-, el militar hispanocriollo entregó a la posteridad una obra escrita titulada El Cauti- 
verio feliz y razón de las dilatadas guerras de Chile. En esta voluminosa obra, por momentos latosa pero no por eso menos interesante e instructiva, el célebre cautivo entregó algunos curiosos y fascinantes detalles en torno al comportamiento de los indígenas ante diversos escenarios y las conductas y reacciones que estos comportamientos podían llegar a generar entre los mismos.

Pineda y Bascuñán sostiene que los mapuches sabían perfectamente que el adulterio, el robo y el asesinato constituían pecado, «que entre ellos llaman huerilcan». Sin embargo, agrega que acciones como las borracheras y las relaciones sexuales con mujeres solteras, que la doctrina católica cataloga como pecados, no constituían para ellos prácticas reprochables que ameritaran algún tipo de censura, juicio o castigo físico o social (Núñez de Pineda 1863: 107).

Al seguir el relato del cautivo hispano, se aprecia claramente que la moral mapuche difería en muchos aspectos de la moral cristiana que los hispanos intentaban aplicar y expandir entre ellos. Y estas diferencias, con respecto a lo que constituye pecado, también se observan en relación a la homosexualidad. Según Pineda y Bascuñán, los mapuches «solo tienen por vil y vituperable el pecado nefando, con esta diferencia, que el que se usa el oficio de varón no es baldonado por él, como el que se sujeta al de la mujer, y a estos los llaman hueies, que en nuestro vulgar lenguaje quiere decir nefandos y más propiamente putos, que es la verdadera explicación del nombre hueies» (Núñez de Pineda 1863: 107).

Aunque la homosexualidad era en general repudiada, es interesante observar que entre los mapuches el repudio y la condena social se dirigían principalmente hacia aquellos que hacían uso del oficio de «mujer» (penetrados), a diferencia de los españoles o de la doctrina cristiana en general que condenaba y castigaba indistintamente a todos los participantes del acto homosexual (penetrados y penetradores). De hecho, según lo escrito por Pineda y Bascunán, los hombres pasivos no usaban los tradicionales «calzones» que empleaban todos los nativos de género masculino, sino que utilizaban, al parecer a modo de identificación, una «mantichuela» a la que llamaban рипи. Conjuntamente, denigrando aún más la condición homosexual, el cautivo sostiene, advirtiéndose en sus opiniones prejuicios propios del cristianismo, que estos hombres que ejercían funciones sexuales de mujeres poseían «pacto con el demonio», por lo que las únicas labores aceptables que podían ejercer era la de «machis o curanderos» (Núñez de Pineda 1863: 107).

En todo caso, al ir observando más objetivamente las formas de vida indígena y al despojarse un tanto de sus católicos prejuicios, el vínculo que el joven militar español realizó entre la práctica homosexual y la función de machi es finalmente deshecho por él mismo, cuando escribe que «estos [machis] verdaderamente no tienen pacto con el espíritu malo». Pero, a pesar de esta leve concesión que «desataniza» el oficio de machi, Pineda y Bascuñán vuelve a cargar sobre los sodomitas señalando que quienes sí poseen tratos con el mal espíritu, causando «pavor y espanto» dentro de la sociedad nativa, son aquellos «otros que llaman huyes [hueies], que son nefandos, como queda dicho» (Núñez de Pineda 1863: 164).

Las tres fuentes citadas, la de Miguel de Olaverría, la de Juan Falcón y la de Francisco Núñez de Pineda y Bascuñán, establecen que aquello que más preocupaba a los españoles sobre los mapuches era la práctica de la poliginia, sin que la homosexua- 
lidad aparezca como una costumbre o un uso masivamente presente en su sociedad. Por el contrario, no es posible conciliar las declaraciones de Barros Arana o Villalobos con lo registrado por los tres autores citados, en especial con Olaverría, quien asegura que entre los rebeldes y valientes araucanos la homosexualidad era castigada con la pena de muerte. Pero si bien no se puede asegurar que la homosexualidad fuera efectivamente penada con la muerte de los infractores, si se puede decir, siguiendo a Núñez de Pineda, que la penetración anal entre varones fue un comportamiento repudiado y condenado socialmente entre los mapuches.

\section{Conclusiones}

Al contrario de lo que sostenía la Antropología del siglo XIX, todas las sociedades indígenas, incluidos los grupos más reducidos como las bandas, mantenían una cultura propia que incluía un marco normativo que debían obedecer todos los miembros de su comunidad. Los estudios antropológicos de Malinowski fueron claves en destacar que la vida de los nativos estaba sometida a estrictas regulaciones, sistemáticas y compartidas por cada comunidad. La consecuencia principal de los estudios del antropólogo polaco fue que ya no se pudo seguir sosteniendo, como se había hecho antes, que la vida en las sociedades indígenas quedaba entregada al azar o a los instintos de individuos que no conocían normas algunas:

«Es creencia popular que los indígenas viven en el seno mismo de la Naturaleza, más o menos como pueden y quieren, víctimas de temores descontrolados y creencias fantasmagóricas. La ciencia moderna, por el contrario, demuestra que sus instituciones sociales tienen una organización bien definida, que se gobiernan con autoridad, ley y orden, tanto en sus relaciones públicas como en las privadas, estando éstas, además, bajo el control de lazos de parentesco y clan sumamente complejos. De hecho, les vemos enredados en una malla de deberes, funciones y privilegios que corresponden a una elevada organización tribal, comunal y de parentesco» (Malinowski 1975: 27).

Toda esta gama de directrices sociales aparece al examinar los registros dejados por los observadores europeos que recorrieron el Nuevo Mundo. Conquistadores y cronistas dieron cuenta de un mundo cultural rico y complejo, que ellos trataban de comprender y del que dieron cuenta no siempre con éxito.

En el caso particular de la actitud de los indígenas frente al sexo entre hombres, los escritores indianos coincidieron al sostener que en cada región del Nuevo Mundo sus habitantes poseían claras actitudes al respecto, que no parecen haber estado mayormente influenciadas por la moral cristiana introducida posteriormente por los españoles. Según se desprende de los documentos consultados, las actitudes de los diversos grupos indígenas que habitaban el continente ante la homosexualidad comportaban siempre algún tipo de velado o manifiesto reproche o castigo social que iba desde el indiferente desdén hasta el aborrecimiento más encarnizado, incluyendo reacciones de menosprecio, burla, marginación, castigo físico e, incluso, la muerte.

Por otra parte, se debe remarcar que las referencias realizadas por los observadores hispanos en ningún caso niegan la presencia de la homosexualidad en América, sino que únicamente hacen patente el rechazo que ésta despertaba. Ya en el siglo XVI, 
Bartolomé de Las Casas reconocía la existencia de indígenas homosexuales, pero, a la par, argumentaba enérgicamente que la presencia del pecado nefando era universal y se daba incluso entre quienes «tienen nombre de cristianos», por lo que su presencia en el Nuevo Mundo, tan grande y lleno de «inmensas naciones», no debía maravillar a nadie (Las Casas 1909: 92-93).

Posteriormente, al ordenar la corona realizar nuevas y cada vez mayores indagaciones sobre el Nuevo Mundo, se fue generando un importante acopio de referencias en torno a la condena social que recaía sobre la homosexualidad en las diversas regiones del continente. Con base en este material, Juan López de Velasco pudo hacer un resumen sobre las provincias indianas con mayores conocimientos y sostener que «en las más o casi todas, aborrecían el pecado nefando» (López de Velasco 1894: 30). Sobre todo, las palabras de Velasco, al igual que aquellas de Las Casas, no constituyen en modo alguno una negación de la existencia de prácticas homosexuales entre los naturales, sino tan sólo una afirmación de que éstas eran aborrecidas socialmente.

En otro plano, el hecho de asumir que todas las acusaciones sobre la presencia de indígenas homosexuales realizadas por los españoles no eran más que una forma de acumular argumentos para conquistarlos, esclavizarlos o imponerles algún otro tipo de explotación, evidencia un total desconocimiento de la institucionalidad vigente en España en el momento de la conquista. Especialmente desde la legislación indiana de Carlos V, el pecado nefando no fue considerado una causa que legitimara acciones como las de conquistar, esclavizar o someter a los naturales del Nuevo Mundo. Para los principales juristas de la época y los que encontraban mayor eco en la corona, «ni el Papa ni príncipe alguno, por causa de los pecados cometidos contra la naturaleza, podían declarar la guerra contra los indios, al ser ilícita e injusta» (García Añoveros 2000: 65).

En definitiva, la documentación existente permite concluir que los tres enfoques historiográficos mencionados en la introducción sobre las actitudes de los indígenas del Nuevo Mundo ante la homosexualidad carecen de suficientes y sólidos fundamentos.

En primer lugar, el argumento que señala que los españoles acusaron a los indígenas de sodomitas con el único objetivo de tener una excusa para poder conquistarlos o esclavizarlos carece de sólidas bases documentales y se contradice con el hecho de que esta acción estaba estrictamente prohibida por la Corona. Además, tal argumento no se hace cargo de los muchos testimonios españoles que, junto con reconocer la existencia de homosexuales en el Nuevo Mundo, también aseguraron que ellos eran castigados y rechazados o despreciados por quienes conformaban su comunidad.

En segundo lugar, las fuentes permiten rebatir la postura que señala que en América no existían prescripciones en contra de las prácticas homosexuales, ya que las observaciones y las opiniones indígenas recogidas por los hispanos señalan claramente que sí las había, y de diverso tipo. Por lo demás, el argumento que pretende legitimar y generalizar la homosexualidad en función de una praxis divina, también queda altamente condicionado, ya que las fuentes señalan tres circunstancias que se deben atender: 1) que la sodomía sólo se practicaba sin ser castigada en algunas pocas provincias; 2) que a pesar de los intentos de ciertos mandos religiosos indígenas por justificarla con base en el ejemplo divino, la práctica era igualmente rechazada 
e, incluso, muchos de quienes la practicaban lo hacían por constituir una obligación impuesta por las autoridades religiosas y no por voluntad propia; y 3) que, a pesar de lo anterior, entre la gran mayoría de las autoridades religiosas indígenas la homosexualidad era altamente rechazada y condenada.

Por último, los registros consultados, aunque refieran que los indígenas americanos rechazaban la homosexualidad, no ocultan que entre ellos había otras prácticas que eran castigadas de igual o peor forma por el cristianismo. Los escritores indianos nunca disimularon que los pueblos del Nuevo Mundo adoraban a sus propios dioses según ritos que, inclusive, podían incluir sacrificios humanos. Por lo tanto, sostener que los testimonios que hablan de la homofobia indígena buscaban congraciarse con la autoridad hispana o que eran el resultado de la aculturación no constituye un argumento válido, puesto que no logra explicar la permanencia de otras acusaciones contrarias a la moral europea.

En síntesis, en los casos analizados la homosexualidad jamás fue una práctica socialmente tolerada o incentivada. Al contrario, las fuentes indican que fue no solo restringida, sino también rechazada, condenada y castigada desde épocas precolombinas. Por lo tanto, los prejuicios, la discriminación y la homofobia en general no fueron en absoluto prácticas iniciadas con el arribo de los conquistadores europeos, sino que existían en América desde mucho antes de su llegada.

\section{Referencia documental}

AGI (Archivo General de Indias, Sevilla)

Patronato, 228, R. 13 «Informe sobre el estado del Reino de Chile», por Miguel de Olaverría, circa 1600 .

\section{Referencias bibliográficas}

Acosta, Joseph de

1894 Historia natural y moral de las Indias. Madrid: Ramón Anglés, impresor.

Alcobiz, Andrés de

1891 «Estas son leyes que tenían los indios de la Nueva España, Anáhuac ó México», en Nueva colección de documentos para la historia de México. Tomo III: Pomar - Zurita-Relaciones antiguas, Joaquín García Icazbalceta, ed., pp. 308-315. México: Imprenta de Francisco Díaz de León.

Allen, James P.

2005 The Ancient Egyptian Pyramid Texts. Atlanta: Society of Biblical Literature.

Alva IxtLILXochitl, Fernando de

1891-92 Obras históricas. México: Oficina Tipográfica de la Secretaría de Fomento.

ANÓNIMO

1879 «Relación anónima de las costumbres antiguas de los naturales del Perú», en Tres relaciones de antigüedades peruanas, pp. 137-227. Madrid: Imprenta y Fundición de M. Tello. 
BACHELARD, Gaston

1997 La formación del espíritu cientifico. México: Siglo XXI.

BAINES, John y Jaromir MÁLEK

1998 Egipto: dioses, templos y faraones. Barcelona: Ediciones Folio.

Barros Arana, Diego

1884-1902 Historia general de Chile, 16 vols. Santiago de Chile: Rafael Jover.

BERnand, Carmen y Serge Gruzinski

1992 De la Idolatría: una arqueología de las ciencias religiosas. México: Fondo de Cultura Económica.

BorJa GómEz, Jaime Humberto

2002 Los indios medievales de fray Pedro de Aguado. Bogotá: CEJA.

BOURDIEU, Pierre

2000 La dominación masculina. Barcelona: Anagrama.

Cieza de León, Pedro

2005 Crónica del Perú. El señorío de los Incas. Caracas: Biblioteca Ayacucho.

Сово, Bernabé

1964 Obras del P. Bernabé Cobo. Madrid: Ediciones Atlas.

FERnÁndeZ DE Oviedo, Gonzalo

1851-55Historia general y natural de las Indias, Islas y Tierra firme del Mar Océano. Madrid: Imprenta de la Real Academia de la Historia.

GARCÍA, Gregorio

1607 Origen de los indios del Nuevo Mundo e Indias Occidentales. Valencia: Casa de Pedro Patricio Mey.

García AÑoveros, Jesús María

2000 «Carlos V y la abolición de la esclavitud de los indios. Causas, evolución y circunstancias». Revista de Indias LX (218): 57-84.

GARCILASO DE LA VEGA, Inca

1976 Comentarios reales de los Incas, 2 vols. Sucre: Biblioteca Ayacucho.

Garza Carvajal, Federico

2003 Butterflies will Burn: Prosecuting Sodomites in Early Modern Spain and Mexico. Austin: University of Texas Press.

GoLDBERG, Jonathan

1991 «Sodomy in the New World: Anthropologies Old and New». Social Text 29: 4656.

GonZÁlez de NÁJERA, Alonso

1889 Desengaño y reparo de la guerra del Reino de Chile. Santiago de Chile: Imprenta Ercilla.

HaRTLAND, Edwin Sidney

1924 Primitive Law. Londres: Methuen.

Howey, Catherine

2007 «The Vain, Exotic, and Erotic Feather: Dress, Gender, and Power in Sixteenthand Seventeenth-Century England», en Religion, Gender, and Culture in the Pre- 
Modern World, Brian Britt y Alexandra Cuffel, eds., pp. 211-240. Nueva York: Palgrave Macmillan.

«Información de las idolatrías...»

1874 «Información de las idolatrías de los incas e indios y de cómo se enterraban, etc. (Año de 1571)», en Colección de documentos inéditos relativos al descubrimiento, conquista y organización de las antiguas posesiones españolas de América y Oceanía, tomo XXI, pp. 131-220. Madrid: Imprenta de Manuel G. Hernández.

LAS CASAS, fray Bartolomé de

1909 Apologética historia de las Indias. Madrid: Bailly-Ballière.

LÉVI-STrauss, Claude

1951 Race et histoire. Paris: UNESCO.

LÓPEZ DE GómARA, Francisco

1979 Historia general de las Indias. Caracas: Biblioteca Ayacucho.

LÓPEZ DE VELASCO, Juan

1894 Geografía y descripción de las Indias. Fortanet: Madrid,

MaLINOWSKI, Bronislaw

1975 Los argonautas del Pacífico occidental, $2^{\text {a }}$ ed. Barcelona: Península.

ManNICHE, Lise

1977 «Some Aspects of Ancient Egyptian Sexual Life». Acta Orientalia 38: 11-23.

MARI, Françoise

1986 «Les Indiens entre Sodome et les Scythes: an aspect de la perception morale des premiers Européens en Amérique». Histoire, économie \& société 5: 3-30.

Molina, Fernanda

2010 «Crónicas de la sodomía. Representaciones de la sexualidad indígena a través de la literatura colonial». Bibliographica Americana 6: 1-12.

2011 «Crónicas de la hombría. La construcción de la masculinidad en la conquista de América». Lemir 15: 186-206.

Muñoz CAMARgo, Diego

1892 Historia de Tlaxcala. México: Oficina Tipográfica de la Secretaría de Fomento.

MurúA, Fray Martín de

1962-64Historia general del Perú. Madrid: Consejo Superior de Investigaciones Científicas.

NúÑez de PINEdA y BASCuñán, Francisco

1863 Cautiverio feliz y razón de las guerras dilatadas de Chile. Santiago de Chile: Imprenta del Ferrocarril.

Oliva de Coll, Josefina

1976 La resistencia indígena ante la Conquista. México: Siglo XXI Editores.

PÉREZ DE RiBAS, P. Andrés

1645 Historia de los Trivmphos de Nvestra Santa Fee entre gentes las mas barbaras y fieras del nuеuо Orbe... Madrid: por Alonso de Paredes.

Rosales, Diego de

1877 Historia general de Chile Flandes Indiano. Valparaíso: Imprenta del Mercurio. 
SAHAGún, fray Bernardino de

1829-30Historia general de las cosas de la Nueva España, 3 tomos. México: Imprenta del Ciudadano Alejandro Valdés.

Sigal, Pete

2005 «The Cuiloni, the Patlache, and the Abominable Sin: Homosexuality in Early Colonial Nahua Society». Hispanic American Historical Review 85 (4): 555-93.

2007 «Queer Nahuatl: Sahagún's Faggots and Sodomites, Lesbians and Hermaphrodites». Ethnohistory 54 (1): 9-34.

Tomás y Valiente, Francisco

1994 «La condición natural de los indios de Nueva España, vista por los predicadores franciscanos». Anuario Mexicano de Historia del Derecho 6: 239-262.

TORQuEMADA, Juan de

1723 Veinte $i$ un libros rituales i monarchia indiana. Madrid: en la oficina de Nicolás Rodríguez.

VÁZQUEZ DE EsPINOSA, Antonio

1948 Compendio y descripción de las Indias Occidentales. Washington: Smithsonian Institution.

Villalobos, Sergio

2006 Historia de los chilenos, Vol. I. Santiago de Chile: Taurus.

ZAPATER, Horacio

1988 «Testimonio de un cautivo. Araucanía 1599-1614». Historia 23: 295-325. Santiago: Pontificia Universidad Católica de Chile.

ZÁrate, Agustín de

1862 «Historia del descubrimiento y conquista de la provincia del Perú y de las guerras y cosas señaladas en ella», en Historiadores primitivos de Indias, tomo 2, pp. 459-563. Biblioteca de Autores Españoles 26. Madrid: Imprenta y Estereotipia Rivadeneyra.

Zorita, Alonso de

1891 «Breve y sumaria relación de los señores y maneras ... de Nueva España», en Nueva colección de documentos para la historia de México. Tomo III: Pomar - Zurita - Relaciones antiguas, Joaquín García Icazbalceta, ed., pp. 71-227. México: Imprenta de Francisco Díaz de León.

1909 Historia de la Nueva España. Madrid: Librería General de Victoriano Suárez. 